Supporting Information

\title{
Hybrid Nanostructures of 2D CdSe Nanoplatelets for High- Performance Photodetector Using Charge Transfer Process
}

\author{
Avisek Dutta, Anusri Medda, Rajesh Bera, Krishnendu Sarkar, Sumanta Sain, Praveen Kumar, \\ and Amitava Patra ${ }^{1 *}$ \\ School of Materials Sciences, Indian Association for the Cultivation of Science, Jadavpur, \\ Kolkata-700032, India \\ ${ }^{1}$ Institute of Nano Science and Technology, Habitat Centre, Sector 64, Phase 10, Mohali 160062, \\ India
}

*To whom correspondence should be addressed. E-mail: $\underline{\text { msap@,iacs.res.in }}$ Phone: (91)-33-2473-4971, Fax: (91)-33-2473-2805 


\section{Preparation of cadmium myristate}

We synthesized cadmium myristate $\left[\mathrm{Cd}(\mathrm{Myr})_{2}\right]$ by following previously published procedures with some modifications. ${ }^{1}$ To prepare cadmium myristate, firstly a solution of sodium myristate was prepared by dissolving $0.43 \mathrm{~g}$ of sodium hydroxide and $3.42 \mathrm{~g}$ of myristic acid in anhydrous methanol $(300 \mathrm{~mL})$. In another beaker, $1.106 \mathrm{~g}$ of cadmium nitrate tetra hydrate was dissolved in $40 \mathrm{~mL}$ methanol. Then, the cadmium nitrate solution was added drop wise into the sodium myristate solution with vigorous stirring at room temperature and a white precipitate of cadmium myristate starts to appear. After the complete addition of cadmium nitrate solution, the reaction was allowed to stir for another $1 \mathrm{hr}$ for completion of the reaction. The precipitate was washed with dried methanol several times to remove unreacted precursors followed by drying at $60^{\circ} \mathrm{C}$ under vacuum overnight.

\section{Characterization}

$\mathrm{UV}-\mathrm{Vis}$ spectrophotometer (Shimadzu) is being used for optical absorption spectra and FluoroMax-P (HORIBA JobinYvon) luminescence spectrophotometer used for the photoluminescence spectra. JEOL-JEM-2100F transmission electron microscope is used for transmission electron microscopy (TEM) images. For time-correlated single photon counting (TCSPC) measurements, all the samples were excited at $371 \mathrm{~nm}$ by picoseconds NANO-LED IBH-375. The fluorescence decays were collected on a Hamamatsu MCP photomultiplier. The following expression was used to analyze the experimental time-resolved fluorescence decays, $P(t)$ :

$$
P(t)=b+\sum_{i}^{n} \alpha_{i} \exp \left(-\frac{t}{\tau_{i}}\right)
$$

Here, $\mathrm{b}$ is the baseline correction ("DC" offset), $\mathrm{n}$ is the number of emissive species, $\alpha_{i}$ is the preexponential factor and $\tau_{i}$ is the excited-state fluorescence decay time associated with the $i^{\text {th }}$ component. The average decay time, $\langle\tau\rangle$, was calculated from the following equation.

$$
<\tau>=\sum_{i=1}^{n} \beta_{i} \tau_{i}
$$

Where $\beta_{i}=\alpha_{i} / \sum \alpha_{i}$ and it is the contribution of the decay component. $\alpha_{i}$ and $\tau_{i}$ are the preexponential factors and excited-state fluorescence lifetimes associated with the $i^{\text {th }}$ component, 
respectively. This value should be called an amplitude-weighted lifetime. Cyclic voltammetric (CV) measurements were done under a nitrogen atmosphere using a $\mathrm{Ag} / \mathrm{Ag}+$ reference electrode, with a Pt disk working electrode and a Pt wire auxiliary electrode, in DCM containing 0.1 M TBAP in a PC-controlled PAR model 273A electrochemistry system. We have used the same fs-transient absorption spectroscopy (TAS) setup which was described elsewhere. ${ }^{2}$ In brief, a mode-locked Ti: sapphire oscillator (Seed laser, Mai-Tai HP, Spectra Physics) generates pulses of $<100$ fs duration at $800 \mathrm{~nm}$, and repetition rate of $80 \mathrm{MHz}$. A separate pump laser $(\mathrm{Nd}$ : YLF laser, $527 \mathrm{~nm}$, ASCEND EX, Spectra-Physics) required for amplifying the seed pulse. The output from the amplifier was ( $800 \mathrm{~nm}, \sim 100 \mathrm{fs}, 1 \mathrm{KHz}$, pulse energy $5 \mathrm{~mJ})$ send to spectrophotometer. BBO crystal was used to generate $400 \mathrm{~nm}$ pump beam for exciting the samples. The other part of the $800 \mathrm{~nm}$ light was focused on $\mathrm{CaF}_{2}$ plate to generate a white-light continuum (WLC) and used as probe pulse. The WLC is also divided into two parts; one part is used as probe pulse and the other one as reference. The reference and transmitted probe beam are then sent to different diode arrays where reference beam helps to account for the intensity fluctuation in white light continuum. The power of pump pulse $\left(<5 \mu \mathrm{J} / \mathrm{cm}^{2}\right)$ was kept low enough to avoid multi-exciton effect and sample degradation. It has to be mentioned that below the $100 \mathrm{fs}$ component can be treated as instrument response function (IRF). All recorded data were fitted using Surface Xplorer version 4.0 software and subsequently chirp was corrected using same software to remove the group velocity dispersion (GVD).

\section{Method of analysis:}

Rietveld method ${ }^{3}$ is regarded as one of the finest methods for crystal structure refinement. Nowadays, its versatility is well recognised which leads to a widespread use of it. This method primarily deals with Marquardt least-squares refinement procedure until the best-fit is achieved between the experimental powder X-ray diffraction (XRD) and computed pattern, based on simultaneously refined models for the crystal structure(s), instrumental factors, diffraction geometry/optics effects, and other sample related characteristics as may be desired and can be modelled. ${ }^{4}$ The residual $\left(S_{y}\right)$, which is minimized in this process is given by

$S_{y}=\sum_{i} w_{i}\left(y_{o i}-y_{c i}\right)^{2}$ 
Where $y_{o i}$ and $y_{c i}$ are the observed and calculated intensities at the $\mathrm{i}$ th point and $w_{i}=\frac{1}{y_{i}}$. The sum is over all the data points. The calculated intensity $\left(y_{c i}\right)$ is expressed as ${ }^{4}$

$y_{c i}=S \sum_{k} L_{k}\left|F_{k}\right|^{2} \phi\left(2 \theta_{i}-2 \theta_{k}\right) P_{k} A+y_{b i}$

Here $S$ represents the scale factor, $k$ is the Miller indices for a Bragg reflection, $L_{k}$ is the Lorentz polarization, $F_{k}$ is the structure factor for the $k$ the Bragg reflection, $\phi$ is the reflection profile function, $P_{k}$ is the preferred orientation function, $A$ is the absorption factor, and $y_{b i}$ is the background intensity for the $i^{\text {th }}$ point. For angle dispersive data the FWHM is modelled using 5 $H=\sqrt{\operatorname{Utan}^{2} \theta+V \tan \theta+W}$

where $U, V$, and $W$ are the refineable parameters. The instrumental broadening is ascertained using a NIST standard SRM 640b.

In the present study, Rietveld program MAUD ${ }^{6}$ is utilized for the whole profile fitting of the

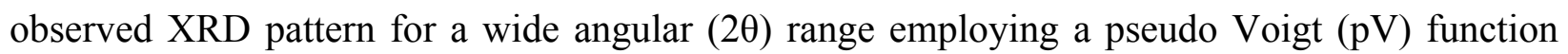
which takes individual care for broadening due to crystallite size and r.m.s. micro strain $\left(\left\langle\varepsilon^{2}\right\rangle^{1 / 2}\right)$. Warren's model ${ }^{7}$ of deformation in the crystal lattice namely- intrinsic $(\alpha)$, extrinsic $(\alpha)$, and twin ( $\beta$ ) faults in the form of probabilities have been included into calculation where $\alpha^{\prime}, \alpha$, and $\beta$ are considered refinable. Successive refinements of different parameters continuous till the convergence is reached and the value of the quality factor, the Goodness of Fit (GoF) reaches unity where GoF is defined as follows.

$G o F=\frac{R_{w p}}{R_{\text {exp }}}$

Where $R_{w p}$ and $R_{\text {exp }}$ represent weighted residual error and expected residual error respectively. 


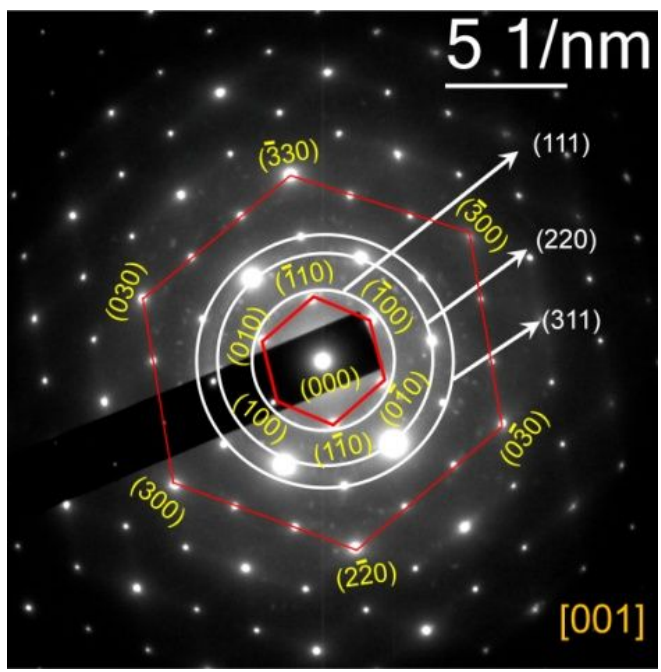

Figure S1. Indexed ring and spotted SAED pattern showing the presence of both ZB and W polytypes respectively. The spotted patterns are indexed using W polytypes along [001] zone axis. In the SAED image, presence of both ring and spot patterns are observed and indexed accordingly (Fig. S1). The ring pattern originates from relatively smaller sized ZB polytypes, however, the diffraction spots arise due to the presence of larger sized W CdSe polytypes. However, it should be noted minor $\mathrm{W}$ polytype has trifle role in the formation of the quantum NPLs.

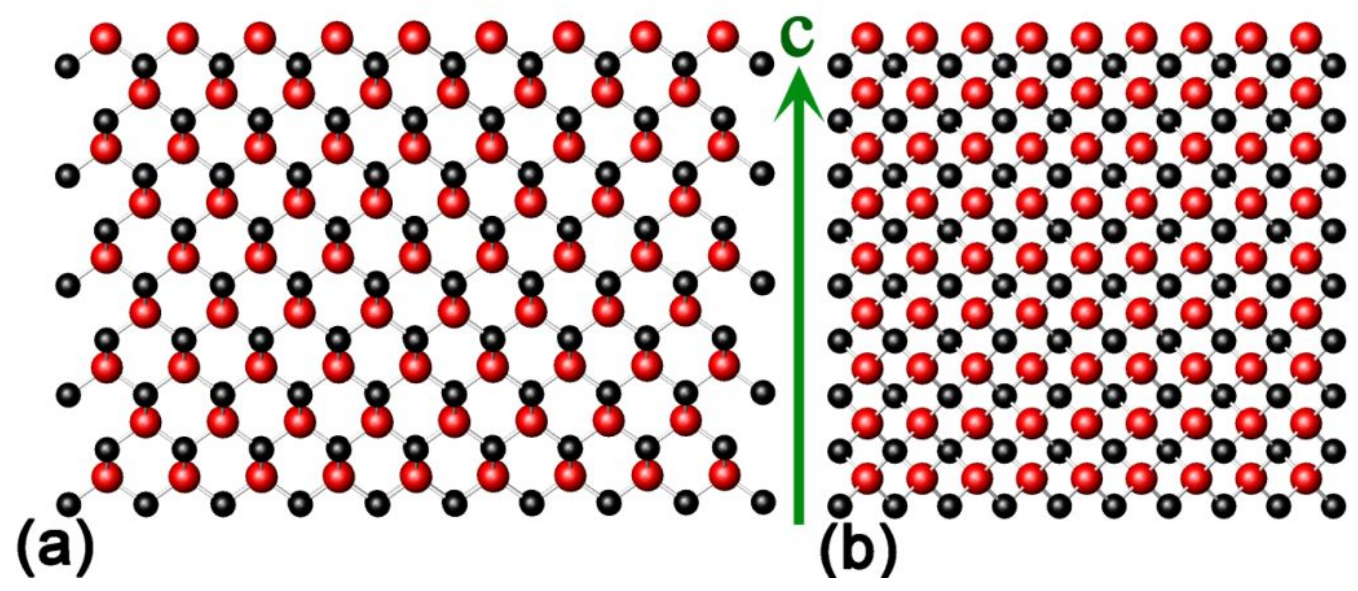

Figure S2. Atomic arrangement of Cd (red sphere) and Se (black sphere) atoms in $<00 \mathrm{c}>$ direction when viewed along (a) parallel and (b) perpendicular to (200) plane of ZB CdSe structure. 


\section{Cyclic voltammetric study}

The measurements were performed at room temperature in an inert atmosphere using a three electrode system consisting of $\mathrm{Pt}$ wire as counter as well as working electrodes and $\mathrm{Ag} / \mathrm{Ag}^{+}$ as reference electrode. From the onset oxidation potential $\left(\mathrm{E}_{\mathrm{ox}}\right)$ and onset reduction potentials $\left(\mathrm{E}_{\mathrm{red}}\right)$ of the nanocrystals, we have calculated VB and $\mathrm{CB}$ energy levels based on the following equations where the potential values are relative to the $\mathrm{Ag} / \mathrm{Ag}+$ reference electrode. $^{8}$

$$
\begin{aligned}
& E_{V B}=-\left(E_{o x}+4.71\right) e V \\
& E_{C B}=-\left(E_{\text {red }}+4.71\right) e V
\end{aligned}
$$
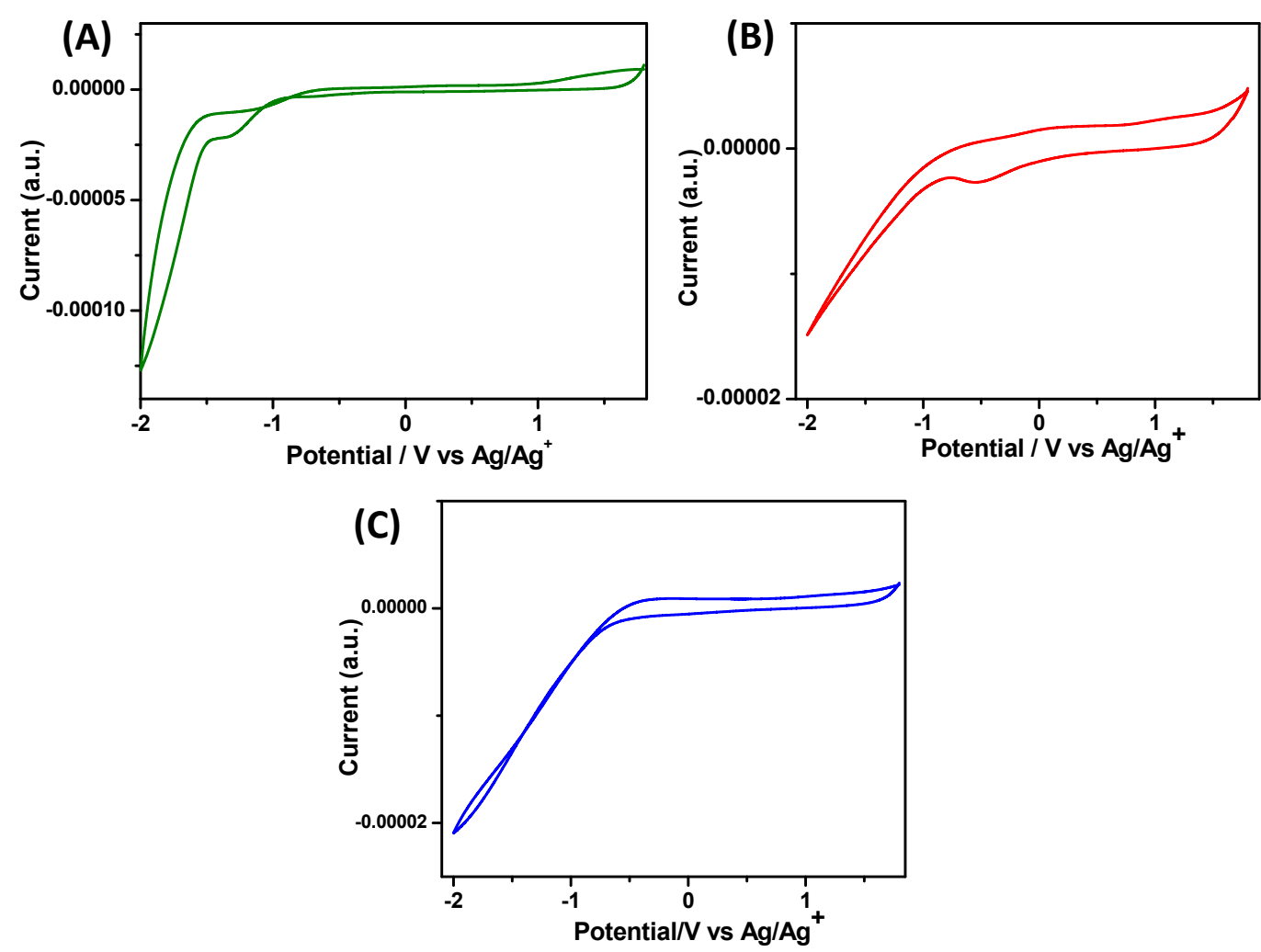

Figure S3: Cyclic voltammograms (CVs) recorded for (A) 3ML CdSe NPLs, (B) 4ML CdSe NPLs and (C) 5ML CdSe NPLs. 


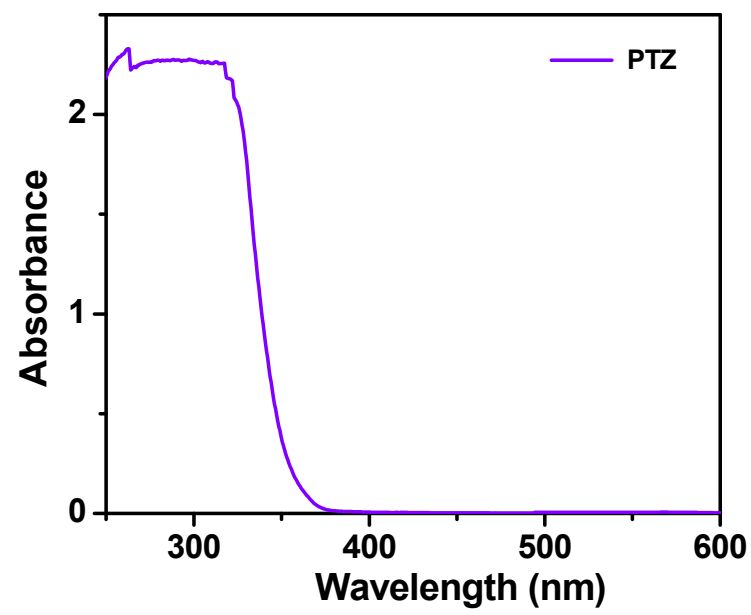

Figure S4: UV-Visible absorbance of phenothiazine (PTZ).

(A)

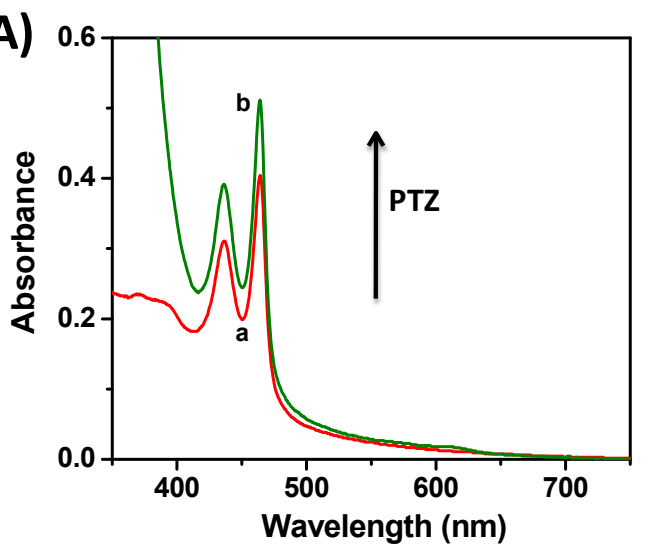

(B)

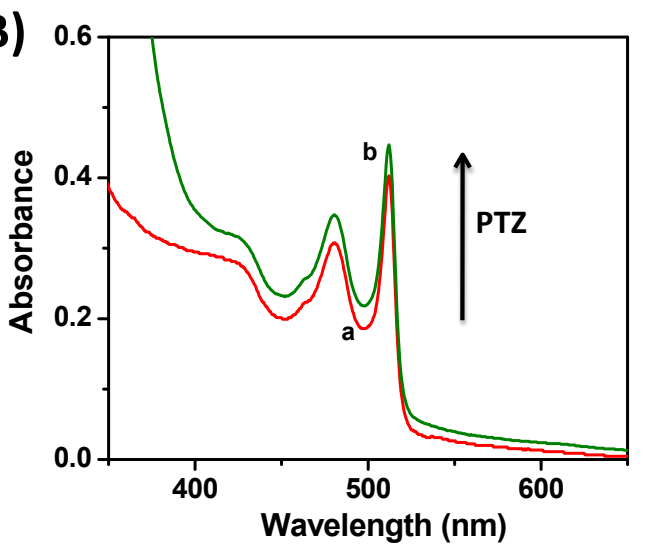

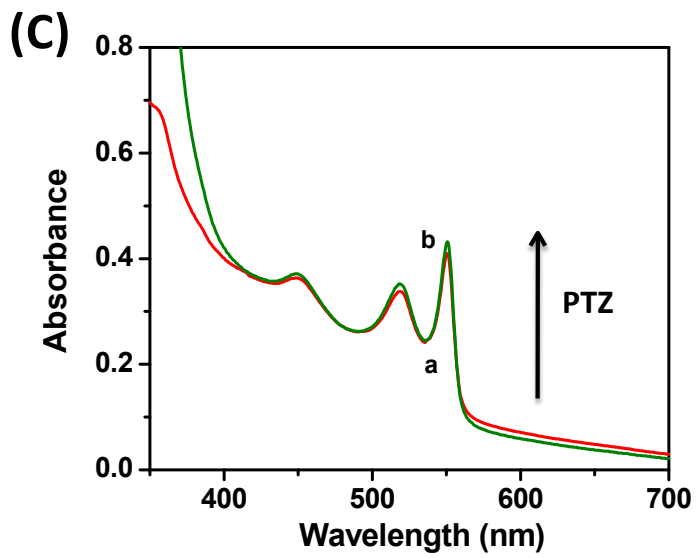

Figure S5: UV-Visible absorbance of (A) 3ML, (B) 4ML and (C) 5 ML CdSe NPLs without PTZ (a) and with PTZ (b). 
Table S1.Decay parameters for pure CdSe NPLs and CdSe NPLs-PTZ

\begin{tabular}{ccccc}
\hline $\begin{array}{c}\text { Sample } \\
(\text { CdSe NPLs })\end{array}$ & $\begin{array}{c}\tau_{1}{ }^{\mathrm{a}}(\mathrm{ns}) \\
\left(\mathrm{a}_{1}{ }^{\mathrm{b}}\right)\end{array}$ & $\begin{array}{c}\tau_{2}{ }^{\mathrm{a}}(\mathrm{ns}) \\
\left(\mathrm{a}_{2}{ }^{\mathrm{b}}\right)\end{array}$ & $\begin{array}{c}\tau_{3}{ }^{\mathrm{a}}(\mathrm{ns}) \\
\left(\mathrm{a}_{3}{ }^{\mathrm{b}}\right)\end{array}$ & $\begin{array}{c}\text { Average } \\
\text { Lifetime } \\
(\mathrm{ns})<\tau>\end{array}$ \\
\hline 3ML & 12.6 & 1.7 & 0.3 & $0.6 \pm 0.1$ \\
$3 \mathrm{ML}+\mathrm{PTZ}$ & $(0.02)$ & $(0.06)$ & $(0.9)$ & \\
& 11.1 & 1.3 & 0.2 & $0.4 \pm 0.1$ \\
$4 \mathrm{ML}$ & $(<0.1)$ & $(<0.1)$ & $(0.9)$ & \\
& 12.0 & 2.3 & 0.4 & $1 \pm 0.1$ \\
$4 \mathrm{ML}+\mathrm{PTZ}$ & $(<0.1)$ & $(<0.1)$ & $(0.9)$ & \\
& 11.4 & 2.2 & 0.4 & $0.8 \pm 0.1$ \\
$5 \mathrm{ML}$ & $(<0.1)$ & $(<0.1)$ & $(0.9)$ & \\
& 13.6 & 2.6 & 0.5 & $1.5 \pm 0.1$ \\
$5 \mathrm{ML}+\mathrm{PTZ}$ & $(<0.1)$ & $(0.2)$ & $(0.8)$ & \\
& 10.2 & 1.0 & 0.3 & $1.1 \pm 0.1$ \\
$\mathrm{a}_{ \pm} 3 \%$ and $\pm 4 \%$ & $(<0.1)$ & $(0.5)$ & $(0.5)$ & \\
\hline
\end{tabular}

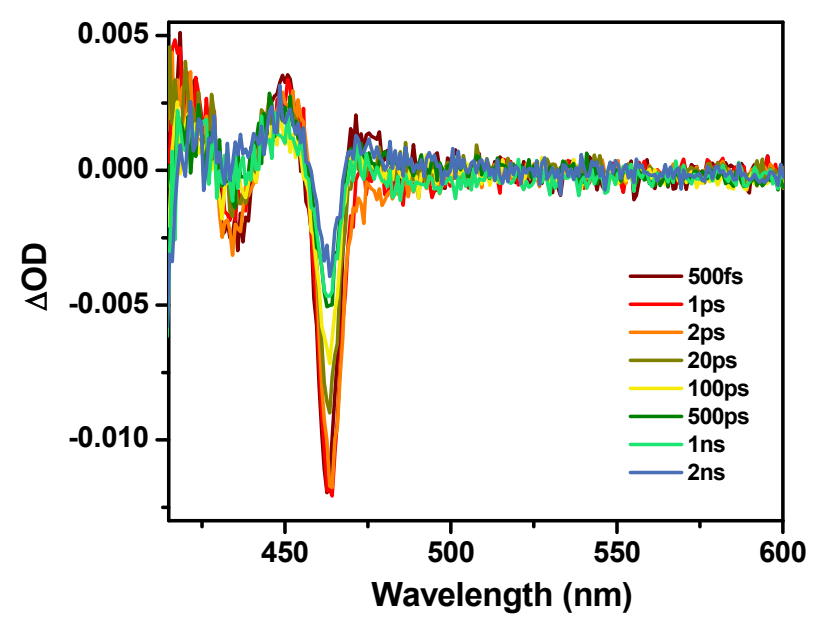

Figure S6: Transient absorption (TA) spectra of pure 3 ML CdSe NPLs at different delay times. 

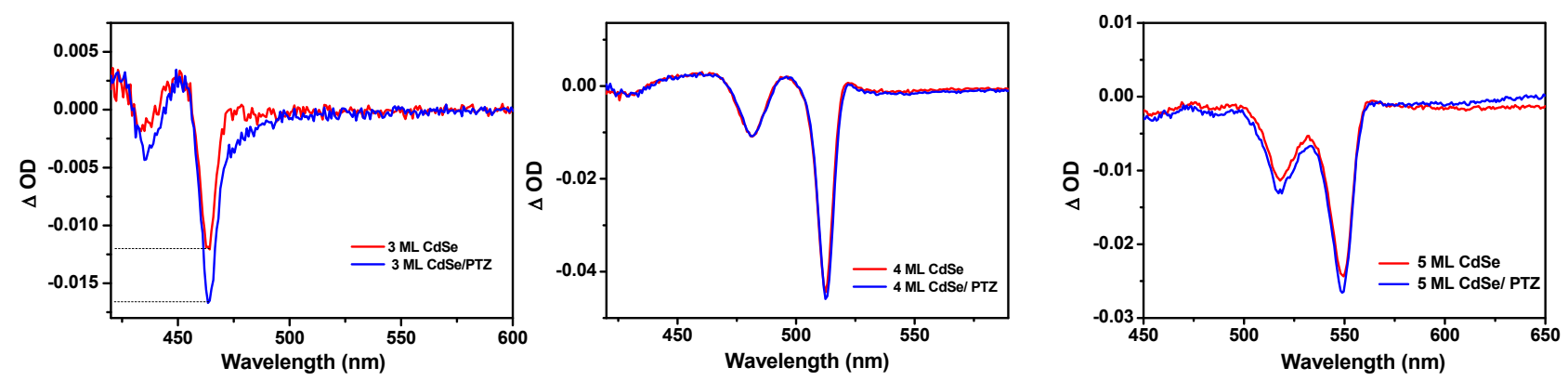

Figure S7: TA evolution data of each system at $1 \mathrm{ps}$ time interval showing the OD amplitude in presence of PTZ molecules.
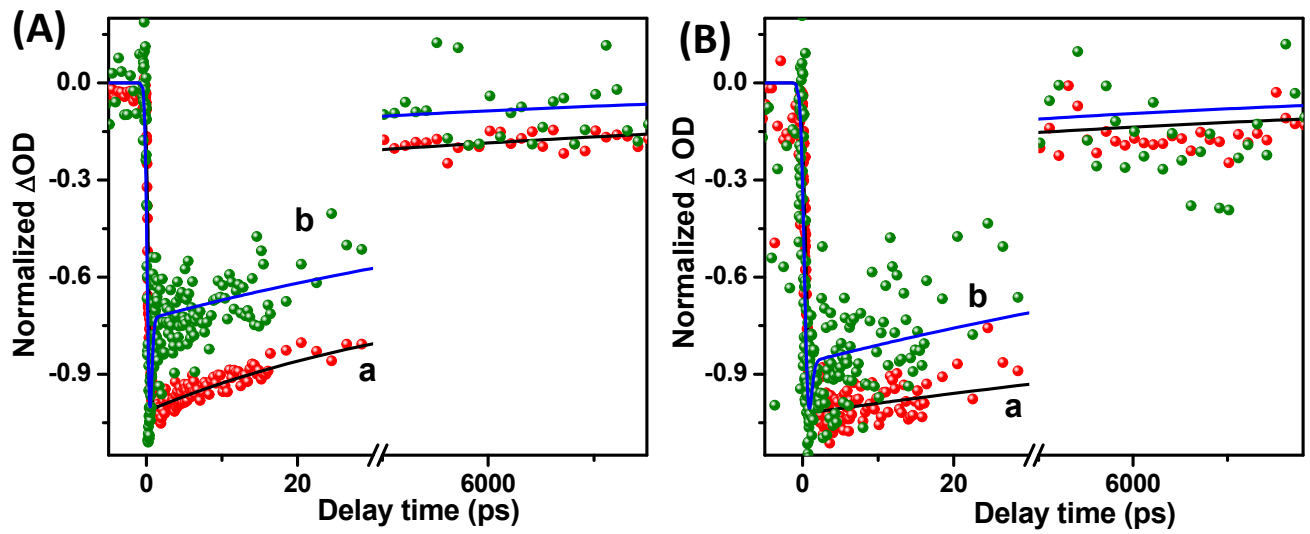

Figure S8: Normalized TA kinetics of (A) 4ML and (B) 5ML CdSe NPLs for (a) heavy hole and (b) light hole. 
Table S2. Fitting parameters for heavy hole and light hole in pure CdSe NPLs

\begin{tabular}{|c|c|c|c|c|c|}
\hline Sample (NPLs) & $\begin{array}{c}\text { Bleach } \\
\text { Position }\end{array}$ & $\tau^{\mathrm{g}}$ & $\tau_{1}{ }^{r}(p s)$ & $\tau_{2}{ }^{r}(p s)$ & $\tau_{3}{ }^{r}(p s)$ \\
\hline 3ML HH & $463 \mathrm{~nm}$ & $<100$ fs & $\begin{array}{l}1.6 \pm 0.1 \\
(25.1 \%)\end{array}$ & $\begin{array}{r}45.6 \pm 0.2 \\
(30.8 \%)\end{array}$ & $\begin{array}{l}>1000 \\
(44.1 \%)\end{array}$ \\
\hline 3ML LH & $434 \mathrm{~nm}$ & - & $\begin{array}{c}<0.1 \\
(99.7 \%)\end{array}$ & $\begin{array}{c}27.1 \pm 0.2 \\
(0.3 \%)\end{array}$ & - \\
\hline $4 \mathrm{ML} \mathrm{HH}$ & $513 \mathrm{~nm}$ & 0.3 & $\begin{array}{c}30.4 \pm 0.2 \\
(26.8 \%)\end{array}$ & $\begin{array}{c}202.0 \pm 1.2 \\
(35.4 \%)\end{array}$ & $\begin{array}{c}>1000 \\
(38.7 \%)\end{array}$ \\
\hline $4 \mathrm{ML} \mathrm{LH}$ & $481 \mathrm{~nm}$ & - & $\begin{array}{c}0.2 \\
(65.5 \%)\end{array}$ & $\begin{array}{c}96.0 \pm 0.6 \\
(34.5 \%)\end{array}$ & - \\
\hline $5 \mathrm{ML} \mathrm{HH}$ & $551 \mathrm{~nm}$ & 0.4 & $\begin{array}{l}62.8 \pm 0.5 \\
(12.8 \%)\end{array}$ & $\begin{array}{c}345.0 \pm 1.3 \\
(52.8 \%)\end{array}$ & $\begin{array}{l}>1000 \\
(34.5 \%)\end{array}$ \\
\hline $5 \mathrm{ML} \mathrm{LH}$ & $519 \mathrm{~nm}$ & - & $\begin{array}{l}0.4 \pm 0.1 \\
(35.2 \%)\end{array}$ & $\begin{array}{c}336.0 \pm 1.3 \\
(64.8 \%)\end{array}$ & - \\
\hline
\end{tabular}



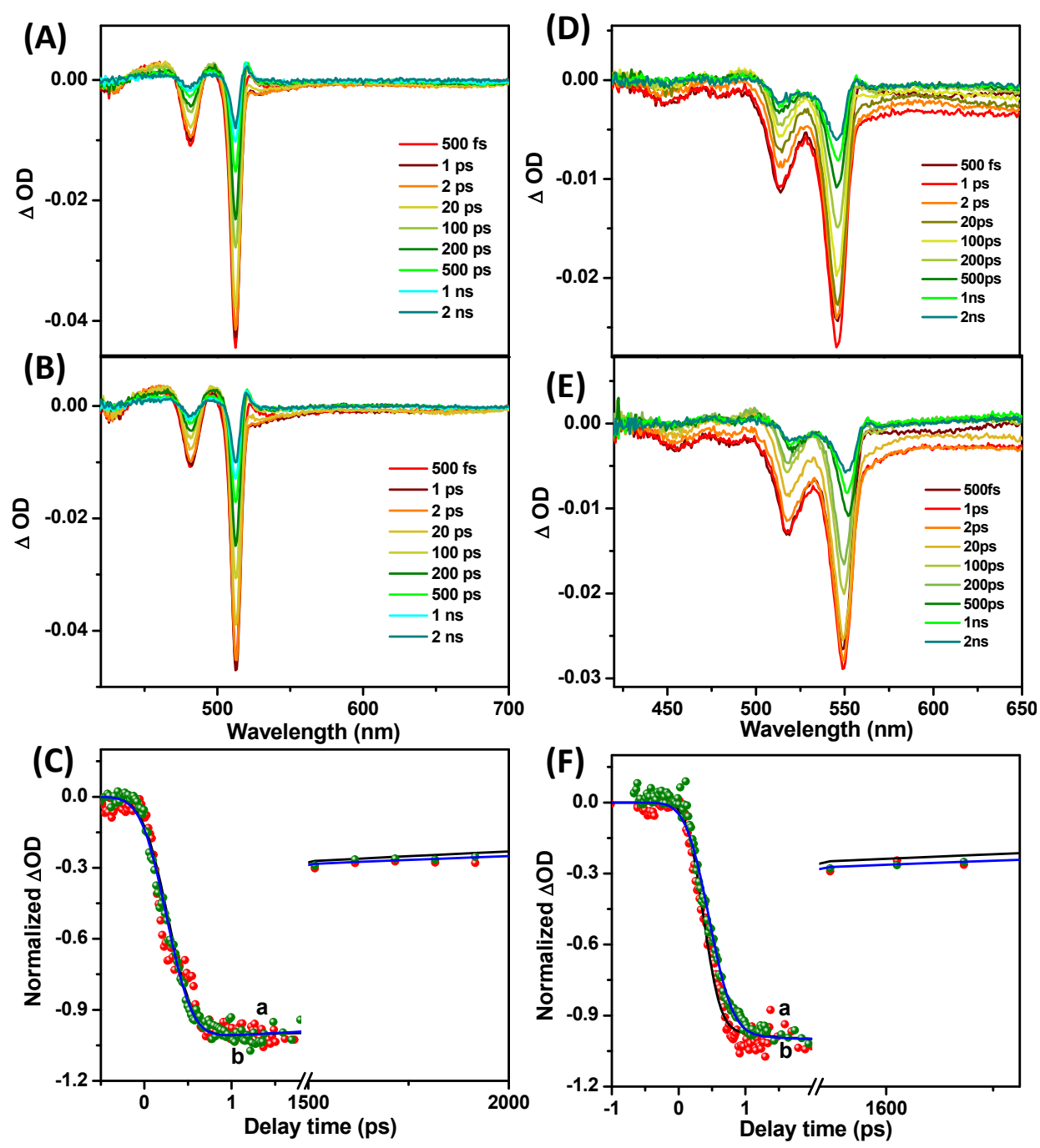

Figure S9: TA spectra of (A) 4 ML CdSe NPLs, (B) 4 ML CdSe NPLs-PTZ hybrid (C) Normalized TA bleaching recovery kinetics of (a) pure 4 ML CdSe NPLs (red) and (b) CdSe-PTZ (olive). TA spectra of (D) 5 ML CdSe NPLs, (E) 5 ML CdSe NPLs with PTZ (F) Normalized TA bleaching recovery kinetics of (a) pure 5 ML CdSe NPLs (red) and (b) CdSe-PTZ (olive). 

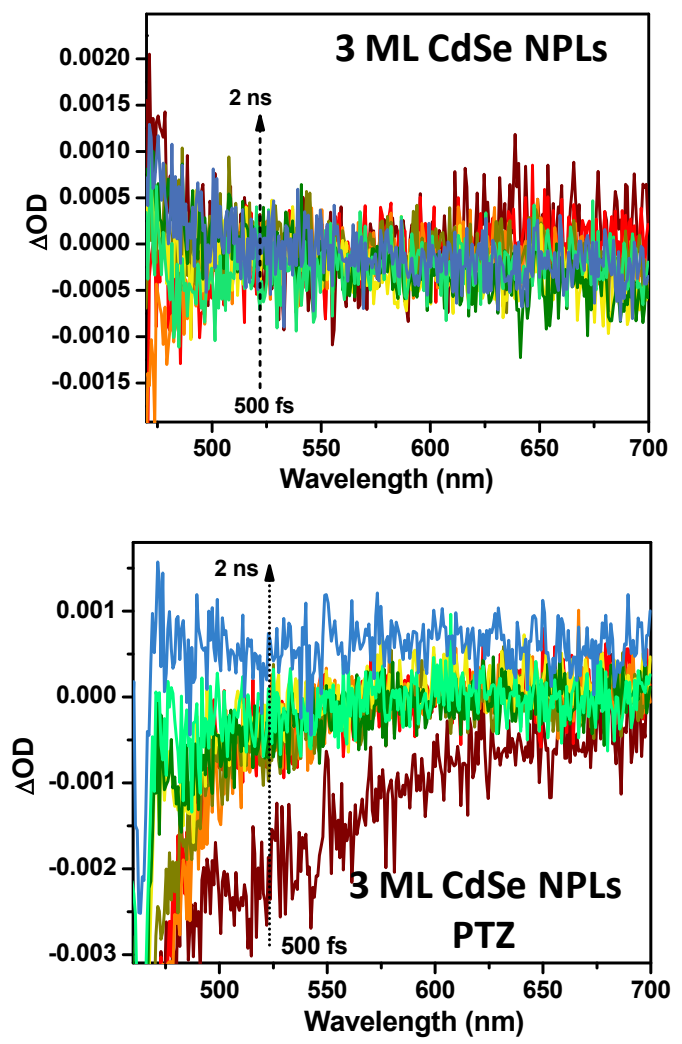

Figure S10: No gradual increment of $\Delta \mathrm{OD}$ value with changing the time interval in case of pure 3 ML CdSe NPLs (above). Gradual increment of $\triangle \mathrm{OD}$ amplitude with time in case of $3 \mathrm{ML} \mathrm{CdSe}$ NPLs/PTZ hybrid (below).

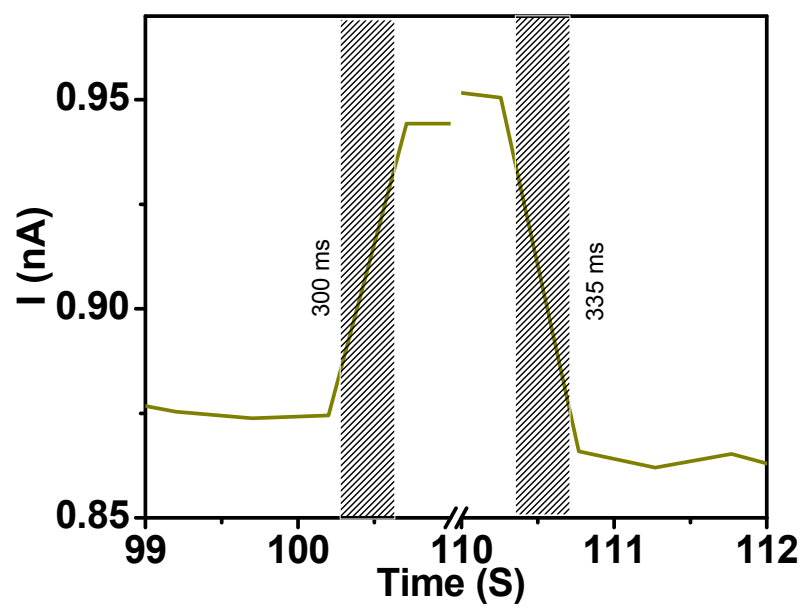

Figure S11: Photo switching properties: rise and fall time of a single ON-OFF scale for pure 3ML CdSe NPLs. 


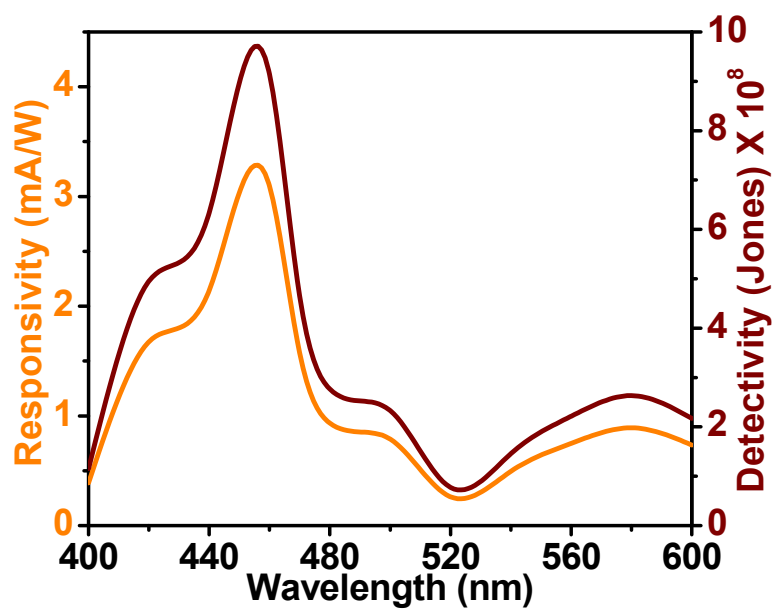

Figure S12: Spectral dependence of photoresponsivity and detectivity of 3ML CdSe NPLs.

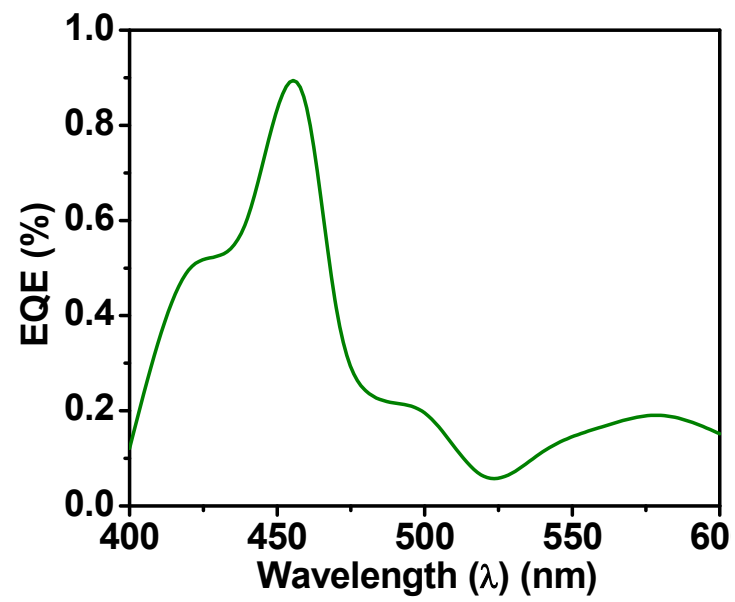

Figure S13: External quantum efficiency of pure 3 ML CdSe NPLs. 
The fabrication cost of CdSe NPLs is almost comparable with the Si. During the synthesis of CdSe NPLs very little amount (few mg) of Cd salt, Se powder and solvent like 1-octadecene and very less amount of oleic acid is needed. Approximate cost of our synthesis is around 0.43 USD only for one batch synthesis, which is cheap even we have purchased all the chemicals from sigma Aldrich. Familiar photodetectors are based on $\mathrm{Si}, \mathrm{Ge}, \mathrm{InGaAs}, \mathrm{GaN}$ semiconductor materials, with high photosensitivity, detectivity, and good stability. Some of them may be expensive or not very easy to synthesize. But, CdSe-PTZ like hybrid can be an option beyond the familiar photodetectors. Total fabrication cost of the hybrid is 0.46 USD only. Therefore, due to the facile and cost-effective synthesis process of these hybrids, CdSe NPLs-PTZ can provide a new avenue on NPLs based photodetectors. Further, based on their advanced optical properties, these hybrids can be used for a variety of optoelectronic applications.

Table S3. Comparison of performance parameters of photodetectors

\begin{tabular}{|c|c|c|c|c|c|c|c|}
\hline $\begin{array}{c}\text { Device } \\
\text { structure }\end{array}$ & Wavelength & Bias & $\mathbf{R}$ & $D^{*}$ & $\begin{array}{l}\text { Rise } \\
\text { time }\end{array}$ & $\begin{array}{c}\text { Decay } \\
\text { time }\end{array}$ & Ref \\
\hline $\begin{array}{l}\text { Si MSM with } \\
\text { CdSe QDs }\end{array}$ & $\begin{array}{c}400-1100 \\
n m\end{array}$ & $50 \mathrm{~V}$ & $\begin{array}{c}0.5 \\
\mathrm{~mA} / \mathrm{W}\end{array}$ & ----- & ----- & ----- & 9 \\
\hline $\begin{array}{l}\text { CdSe quantum } \\
\text { wires }\end{array}$ & $400-700 \mathrm{~nm}$ & $40 \mathrm{~V}$ & $\begin{array}{c}1.8 \\
\mathrm{~mA} / \mathrm{W}\end{array}$ & ---- & ----- & ------- & 10 \\
\hline $\begin{array}{c}\mathrm{CdSe} / \mathrm{CdS} / \mathrm{ZnS} \\
\text { film }\end{array}$ & $532 \mathrm{~nm}$ & $1 \mathrm{~V}$ & $\begin{array}{c}5.88 \\
\mathrm{~mA} / \mathrm{W}\end{array}$ & ---- & $3.5 \mathrm{~ns}$ & $3.5 \mathrm{~ns}$ & 11 \\
\hline CdSe QD & $522 \mathrm{~nm}$ & $2 \mathrm{~V}$ & $\begin{array}{c}10.23 \\
\mathrm{~mA} / \mathrm{W}\end{array}$ & $\begin{array}{c}8.8 \times 10^{9} \\
\text { Jones }\end{array}$ & $\begin{array}{c}17.9 \\
\mathrm{~ms}\end{array}$ & $18 \mathrm{~ms}$ & 12 \\
\hline CdSe QD & Visible & --- & $\begin{array}{c}100 \\
\mathrm{~mA} / \mathrm{W}\end{array}$ & $\begin{array}{c}7.06 \times 10^{7} \\
\text { Jones }\end{array}$ & ---- & ----- & 13 \\
\hline $\begin{array}{c}\mathrm{TiO} \\
\text { nanowell/organic } \\
\text { hybrid }\end{array}$ & $320 \mathrm{~nm}$ & $1 \mathrm{~V}$ & $\begin{array}{c}3.6 \\
\mathrm{~mA} / \mathrm{W}\end{array}$ & ---- & $3.8 \mathrm{~ms}$ & $30.7 \mathrm{~ms}$ & 14 \\
\hline $\begin{array}{c}\text { CdSe NPLs-PTZ } \\
\text { hybrid }\end{array}$ & $400-600 \mathrm{~nm}$ & & $\begin{array}{c}160 \\
\mathrm{~mA} / \mathrm{W}\end{array}$ & $\begin{array}{l}4 \times 10^{11} \\
\text { Jones }\end{array}$ & $107 \mathrm{~ms}$ & $110 \mathrm{~ms}$ & This work \\
\hline
\end{tabular}




\section{References:}

1. Tessier, M. D.; Spinicelli, P.; Dupont, D.; Patriarche, G.; Ithurria, S.; Dubertret, B., Efficient Exciton Concentrators Built from Colloidal Core/Crown CdSe/CdS Semiconductor Nanoplatelets. Nano Lett. 2014, 14, 207-213.

2. Bera, R.; Dutta, A.; Kundu, S.; Polshettiwar, V.; Patra, A., Design of a CdS/CdSe Heterostructure for Efficient $\mathrm{H}_{2}$ Generation and Photovoltaic Applications. J. Phys. Chem. C 2018, 122, 12158-12167.

3. Rietveld, H., A Profile Refinement Method for Nuclear and Magnetic Structures. Journal of Applied Crystallography 1969, 2, 65-71.

4. Meulenberg, R. W.; van Buuren, T.; Hanif, K. M.; Willey, T. M.; Strouse, G. F.; Terminello, L. J., Structure and Composition of Cu-Doped CdSe Nanocrystals Using Soft X-Ray Absorption Spectroscopy. Nano Lett. 2004, 4, 2277-2285.

5. Caglioti, G.; Paoletti, A.; Ricci, F. P., Choice of Collimators for a Crystal Spectrometer for Neutron Diffraction. Nuclear Instruments 1958, 3, 223-228.

6. Anikeeva, P. O.; Halpert, J. E.; Bawendi, M. G.; Bulović, V., Quantum Dot Light-Emitting Devices with Electroluminescence Tunable over the Entire Visible Spectrum. Nano Lett. 2009, 9, 2532-2536.

7. An, X.; Liu, F.; Jung, Y. J.; Kar, S., Tunable Graphene-Silicon Heterojunctions for Ultrasensitive Photodetection. Nano Lett. 2013, 13, 909-916.

8. Bera, R.; Jana, B.; Mondal, B.; Patra, A., Design of CdTeSe-Porphyrin-Graphene Composite for Photoinduced Electron Transfer and Photocurrent Generation. ACS Sustainable Chemistry \& Engineering 2017, 5, 3002-3010.

9. Chou, C.-M.; Cho, H.-T.; Hsiao, V. K. S.; Yong, K.-T.; Law, W.-C., Quantum Dot-Doped Porous Silicon Metal-Semiconductor Metal Photodetector. Nanoscale Res. Lett. 2012, 7, 291.

10. Singh, A.; Li, X.; Protasenko, V.; Galantai, G.; Kuno, M.; Xing, H.; Jena, D., PolarizationSensitive Nanowire Photodetectors Based on Solution-Synthesized CdSe Quantum-Wire Solids. Nano Lett. 2007, 7, 2999-3006.

11. Pourret, A.; Guyot-Sionnest, P.; Elam, J. W., Atomic Layer Deposition of ZnO in Quantum Dot Thin Films. Adv. Mater. 2009, 21, 232-235. 
12. Kumar, H.; Kumar, Y.; Mukherjee, B.; Rawat, G.; Kumar, C.; Pal, B. N.; Jit, S., Electrical and Optical Characteristics of Self-Powered Colloidal CdSe Quantum Dot-Based Photodiode. IEEE J. Quantum Electron. 2017, 53, 1-8.

13. Hegg, M. C.; Horning, M. P.; Baehr-Jones, T.; Hochberg, M.; Lin, L. Y., Nanogap Quantum Dot Photodetectors with High Sensitivity and Bandwidth. Appl. Phys. Lett. 2010, 96, 101118.

14. Hussain, A. A.; Sharma, B.; Barman, T.; Pal, A. R., Self-Powered Broadband Photodetector Using Plasmonic Titanium Nitride. ACS Appl. Mater. Interfaces 2016, 8, 4258-4265. 